\title{
ANALYZING VOCABULARY LEVEL OF THE STUDENTS' ESSAY WRITING AND ACADEMIC TEXTBOOK UTILIZING LEXTUTOR
}

\author{
Nur Aliyah Nur \\ nuraliyabnur.uin05@gmail.com
}

\begin{abstract}
The objectives of this study were to describe the result of the vocabulary level analysis of the students' essay writing and academic textbook utilizing lextutor, to investigate the effects of introducing VP web tool (lextutor) on students' vocabulary level in writing academic essays at the English Education Department of UIN Alauddin Makassar academic year 2011/2012, to correlate the vocabulary level of their essay writing and their academic textbook, and to investigate their opinion on lextutor as a VP web tool analyzer towards their essay writing. The data were collected through the VP web tool and interview using four different academic essays of 100 students involved. The data analysis and interpretation indicated: (1) the vocabulary levels of the students' essay writings were smaller than the standard percentage of VP web tool exclude their K1; (2) the changes of vocabulary profile of the students' academic essays were not significantly affected by the introducing of VP web tool as the trendlines did not show the normal pattern of time-series graphic line design; (3) findings on vocabulary profile of the students' academic reading text showed similar patterns of graphic trendline to those in the academic essays; (4) the use of K2 and AWL in the students' academic essays were proved to be significantly different before and after the intervention but not significant in K1 and OL vocabulary profile; (5) there is not any significant correlation between the vocabulary profile of academic reading texts and vocabulary profile of students' essay writing in academic word list; and (6) the VP web tool is good and gives a lot of benefit to students to assess their vocabulary level when dealing with academic essay writing, and they have awareness of using more and appropriate academic vocabulary in writing academic tasks. The findings led to the recommendation of an extensive use of VP web tool to analyze vocabulary level used by students in their academic essays.
\end{abstract}

KEY WORDS: vocabulary level, common words, academic word lists, off-list vocabulary, vocabulary profile, vocabulary web tool, lextutor, academic essays

\section{A. BACKGROUND}

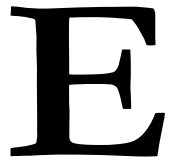

nglish for academic purpose requires a deep understanding of the content area in academic context. In this case, the university students have a great deal of academic requirements in involving, performing and 
Nur Aliyah Nur, Analyæing Vocabulary Level Of The Students' Essay Writing and Academic ...

conducting their academic study and tasks. One of the hard learning activities and tasks to fulfill is writing, especially for academic context such as academic writing.

In this study, the researcher is interested in using writing to measure the students' language proficiencies. Understanding the students' language proficiencies enables the teacher and other educational practitioners to assess the effectiveness of certain subjects or language programs and design a better language program and subject for further language learning activities. Assessing students' language ability through writing also enables the teacher to examine the extent to which the students' understanding of the learning materials that they have learnt. In this case, the researcher focuses on the vocabulary level of the students' writing.

Nation (1990) argued that in vocabulary level, there have been two types of frequency counts of university texts. One type is assumed as a basic vocabulary or most frequent vocabulary like the General Service List, and the second type is assumed as the low frequent vocabulary like the Academic Word List and Technical Term / OffList. To strengthen the assumption, Nation (2001) said that the university textbooks contain at least $10 \%$ academic vocabulary from various kinds of vocabulary level. Based on that assumption, the researcher is also interested to investigate the vocabulary level of the academic reading texts that the students read them frequently and the relationship between the reading frequency of the university students and their vocabulary level of their writing.

Based on Nation's (2001) research on vocabulary for several years, those vocabulary levels cover three levels of vocabulary: high-frequency words, lowfrequency words, and technical words. High-frequency words are defined as words which appear in all types of texts and entail $80 \%$ of a text (Nation, 2001). A few examples of high-frequency words are clock, days, message, decision, and so forth. On the other hand, low-frequency words consist of "a very large group of words that occur very infrequently and cover only a small portion of any text" (Nation, 2001: 19). He also points out that approximately $2 / 3$ of these words are of Latin, French, or Greek origin. Technical vocabulary is the type of low-frequency vocabulary which is used in a specific subject area. Academic vocabulary consists of a type of lowfrequency vocabulary typically used in an academic environment for such purposes as participating in classes and writing research and studies. To facilitate access to these specific words, Coxhead (2000: 254) compiled a list of the more frequent words found in academic texts, and created the Academic Word List (AWL), which consists of 570 word families selected from a “3,500,000 token corpus of academic English". 
By word families it is meant that a word (for instance, clarify) as well as its inflections (clarified, clarifies, and clarifying) and derivations (clarification) are included. The words included on the AWL list were selected from arts, science, law, and commerce texts.

There are many ways of assessing and analyzing vocabulary levels and there are many kinds and sources of them. Considering the validity and reliability of the analyzing tools, many researchers used computer to assess and analyze the vocabulary level with various kinds of analyzing software or tools. In addition, many researchers had conducted analyzing vocabulary levels research of written material such as: text book, research abstract, magazine, and so forth but no one concerned about analyzing the vocabulary levels directly from the students' writing and asked the students' opinion on that analyzing tool. Now that, the researcher is interested in analyzing vocabulary levels of students' writing with the consideration of some previous experts' views and also examine the students' opinion on that analyzing usefulness to their vocabulary learning and assessment. In this case, the researcher utilized internet website as a tool in analyzing the vocabulary levels of students writing namely lextutor developed from Bafia Laufer and Paul Nation (1995) off-line version known as "Range" by Thomas Michael Cobb (2002).

Based on the background described above, the problem to this research was the description of the analysis result of vocabulary levels of the $6^{\text {th }}$ semester students at Alauddin State Islamic University (UIN) Makassar academic year 2011/2012 of their writing and academic textbook utilizing lextutor as well as the students' opinion on that analyzing usefulness to their vocabulary learning and assessment. To be able to have a clear description of it, the researcher posed the following research questions: (1) what were the vocabulary levels of the students' essay writing and their academic textbook based on the analysis result of lextutor?, (2) were there any significant differences among the vocabulary levels of the students' essay writing before and after introducing lextutor?, (3) was there any correlation between the vocabulary level of the students' essay writing and their academic textbook in term the academic word list? and (4) what were the students' opinions on lextutor as a VP web tool analyzer towards their essay writing?

This study was aimed at describing the result of the vocabulary level analysis of the students' essay writing and academic textbook utilizing lextutor, the effect of introducing the web on the vocabulary level of the students' writing, and the opinion of the $6^{\text {th }}$ semester students at Alauddin State Islamic University (UIN) Makassar 
Nur Aliyah Nur, Analyzing Vocabulary Level Of The Students' Essay Writing and Academic ...

academic year $2011 / 2012$. The specific objectives of this research are: (1) to examine the students' vocabulary levels in essay writing and their academic textbook utilizing lextutor, (2) to examine the differences among the vocabulary levels of the students' writing before and after introducing lextutor, (3) to examine the correlation of vocabulary level between the students' essay writing and their academic textbook in term the academic word list, and (4) to investigate the students' opinions on lextutor as a VP web tool analyzer towards their essay writing.

\section{Review of Related Literature}

Analyzing the vocabulary level of the students' essay writing and their academic textbook utilizing lextutor presented an enormous obstacle without any ideas and concepts taken from some resources. A number of studies have been conducted related to the analyzing activities, vocabulary levels, and ICT utilizations.

Mukundan and Hussin, (2006) used WordSmith 3.0 concordance software to evaluate ESL textbooks in providing some insights into the structure of the textbooks and seeking the strengths and weaknesses of that textbooks. The vocabularies used in the textbooks are examined to see the consistency ratio of the textbook. Chen, et al. (2009) conducted a study of academic vocabulary used in the abstracts of business and management journals. They found that the major findings of this study were that academic word list (AWL) vocabulary was frequently used in B \& M journal abstracts and that the abstracts of the international B \& M journals used many more academic words than the English abstracts of Taiwanese journal papers. In one of Chujo and Oghigian's studies (2009), using his self-created nonfiction corpus of TOEFL and TOEIC preparation tests to gauge vocabulary levels of the proficiency tests with the assumed text coverage of $95 \%$ in the BNC HFWL $1^{\text {st }}-14^{\text {th }} 1000$-word levels, TOEFL is reported to hold more vocabulary than TOEIC (6,000 -6,500 vocabulary level for TOEFL versus 4,500 -5,000 level for TOEIC).

The research findings that inspires this research most is the research findings of Aziez (2011). His research aimed to analyze the vocabulary levels of junior and senior high school English National Examination texts. Aziez (2011) suggested the findings of his present study of "examining the vocabulary levels of Indonesia's students' national examination texts" can be beneficial in raising awareness among teachers, textbook writers, and test constructors of the importance of vocabulary level when writing textbooks and constructing tests. 
This research, analyzing vocabulary level of students' essay writing and academic textbook, was related to some ideas from many experts and researches that support and pertinent to this study. Those pertinent ideas are: (1) teaching and learning vocabulary, (2) the types of vocabulary learning, (3) the number of vocabularies the students need to know, (4) vocabulary level analysis, (5) the role of academic vocabulary for university students, (6) vocabulary and writing, (7) vocabulary and reading, (8) the relation among vocabulary, reading, and writing, (9) computer assisted language learning (CALL), (10) the role of computer/ICT in language learning, and (11) computer assisted vocabulary learning.

\section{Method of the Research}

This research used mixed method with QUAN-Qual model design or known as explanatory mixed method design. Gay, et al. (2006) argued that mixed method designs combine quantitative and qualitative approaches by essentially mixing both quantitative and qualitative data in a single study. The purpose of mixed methods research is to build on the synergy and strength that exists between quantitative and qualitative research methods in order to understand a phenomenon more fully than is possible using either quantitative or qualitative methods alone.

Based on the research design, the researcher collected the quantitative data first by using descriptive and correlational method and data analysis by examining the percentage of the vocabulary level of students' writing and their academic textbook and then correlating between the vocabulary level percentage of students' writing and their academic textbook that they read most frequently. In addition, the researcher also collected the quantitative data by using experimental method by examining the effect on introducing lextutor on the vocabulary level of the students' essay writing.

\section{Findings and Discussions}

The data findings consists of (1) vocabulary profiles of the students' (a) essay writing and (b) academic textbooks; (2) comparison of the vocabulary levels of the students' essay writing before and after the treatment in four laps time-series (known as series of pretests and posttests); (3) correlation between the vocabulary level of the students' essay writing and their academic textbook in term academic word list; and (4) the students' opinions on (a) the functional issues of VP web tools to their vocabulary learning and assessment, and (b) their changes of word choices in writing academic essays. 
Nur Aliyah Nur, Analyzing Vocabulary Level Of The Students' Essay Writing and Academic ...

The number of students participated in this reserach was 100 and the total number of the students' essay writing and reading text samples was 400 pieces (100 pieces for in each serial). The VP analysis falls into four categories, namely the use of K1 (most common words level 1), K2 (common words level 2), AWL (academic word list), and OL (off-list/non-English words).

To value the vocabulary level of the students' essay writing scores in academic perspectives, the use of $\mathrm{K} 1$ should be at maximum or less than $70 \%$ of all words produced; K2 should be at minimum or more than $10 \%$ of all words; AWL should be at minimum or more than $10 \%$ of all words; and the same is true for the OL that should be at minimum or more than $10 \%$ of all words produced. In order that the flow of ideas of this chapter to be more readable, the researcher decided to interpret and discuss the findings subsequently in the same heading.

\section{a. Vocabulary Profiles of the Students' Essay Writing and Academic Reading} Texts

\section{1) Vocabulary Profiles of the Students' Essay Writing}

The data in Table 1 summarizes the VP web tools analysis results in lextutor which is used to describe the students' vocabulary profiles of four essay writing and four academic reading textbooks.

Table 4.1. Summary of Students VP in Four Essay Writing

\begin{tabular}{lcccc}
\hline \multicolumn{1}{c}{ Essay Series } & $(\overline{\mathbf{X}}) \mathbf{K}$ 1 & $(\overline{\mathbf{X}}) \mathbf{K} 2$ & $(\overline{\mathbf{X}})$ AWL & $(\overline{\mathbf{X}}) \mathbf{O L}$ \\
\hline Essay1/Pretest 1 & 83.22 & 8.31 & 4.74 & 3.75 \\
Essay 2/Pretest 2 & 80.56 & 6.31 & 5.39 & 7.73 \\
Essay 3/Posttest 1 & 79.15 & 6.96 & 6.20 & 7.68 \\
Essay 4/Posttest 2 & 84.15 & 2.94 & 9.44 & 3.46 \\
\hline
\end{tabular}

Based on the table above, it is inferred that the students' vocabulary levels are still smaller or no more than the standard percentage of VP web tool vocabulary level analyzer $(70 \%, 10 \%, 10 \%$, and 10\%) exclude the first 1000 common words (K1). It seems that the students used more than $70 \%$ common words in their four essay writings. In term of academic essay writing, using at least $10 \%$ academic words is fully recommended.

As Nation \& Waring (2004) stated that the most frequent 2000 words in English are the most useful, for knowing these would allow learners a good degree of comprehension (around $80 \%$ ) of what they hear or read. Research by Liu Na and 
Nation (1982, as stated in Nation \& Waring, 2004), on the other hand, showed that knowing the 2000 words only is not sufficient for overall comprehension, arguing at least 95 percent coverage is needed for a good comprehension of a text. Coxhead (2000) came up with a list of specialized vocabulary consisting of 570 word families most frequently occurring in academic texts. It is asserted that knowing these words in the Academic Words List (AWL), in addition to 2000 most frequent words (the GSL), would be a good basis for learning English for academic purposes (Nation, 2001). Nation also proposes that since these words of high frequency are clearly crucial, teachers and learners should place considerable emphasis on them especially when time is limited, such as the case of intensive pre-sectional university preparatory programmes in non-English speaking countries.

Coxhead (2000) argued that successful adolescent students in content area classrooms share a common characteristic; they have rich academic vocabularies with words that serve them as potent tools for learning in content area classrooms. Based on Coxhead (2000) point of view, academic vocabulary has an important role for university student because it makes the student easier to understand their academic written material and fulfill their tasks. Academic vocabulary helps the students to understand the content area of their study. Thus, the university students should know and master academic vocabulary along with the general vocabulary that they used in their daily communication.

\section{2) Vocabulary Profile of Academic Reading Texts}

The academic reading texts are four different reading materials that the students mostly read before the tests. It was expected that the students would have sufficient academic vocabulary in their mind from a series academic reading texts before taking a series of test administered by the researcher.

Table 2 below summarizes the mean scores of VP percentage of the students' four different academic reading texts in four categories; K1, K2, AWL and OL.

Table 4.2. Summary of Students VP in Four Reading Textbooks

\begin{tabular}{ccccc}
\hline Reading Text Series & $(\overline{\mathbf{X}}) \mathbf{K} 1$ & $(\overline{\mathbf{X}}) \mathbf{K} 2$ & $(\overline{\mathbf{X}})$ AWL & $(\overline{\mathbf{X}})$ OL \\
\hline Reading Text 1/Pretest 1 & 70.26 & 3.44 & 8.38 & 17.91 \\
Reading Text 2/Pretest 2 & 82.84 & 2.22 & 9.91 & 5.03 \\
Reading Text 3/Posttest 1 & 72.39 & 2.83 & 19.35 & 5.43 \\
Reading Text 4/Posttest 2 & 78.85 & 3.31 & 12.48 & 5.35 \\
\hline
\end{tabular}


Nur Aliyah Nur, Analyzing Vocabulary Level Of The Students' Essay Writing and Academic ...

Based on the series analysis results of vocabulary level of academic textbook above, those four academic textbook are qualified enough to be academic input for the university students since the vocabulary levels are closer to the standard percentage of vocabulary levels especially in term academic word list (AWL). Those results are in line with many experts argumentation that perhaps all academic textbooks contain the sufficient vocabulary as the great input for the students' vocabulary not only in common word terms but also in academic words. Those four academic textbooks are proper to be the university students' academic textbook.

\section{b. The differences among the vocabulary levels of the students' essay writing}

The findings of the differences among the students' essay writings pre- and post intervention indicate the use of K2 and AWL in the students' academic essays were proved to be significantly different before and after the intervention but not significant in K1 and OL vocabulary profile. These findings were supported by the perspective of the students from the interview that they found that their vocabulary levels were still low so that they try to change their word choices in writing.

\section{c. The correlation between the vocabulary level of the students' writing and} their academic textbook in academic word list

One of the main concern of this research is to test the hypothesis of the correlation between the vocabulary profile of the academic reading texts and the vocabulary profile of students' essay writing in terms of academic word list (AWL). The study assumed alternative hypothesis that there is a significant correlation between the vocabulary profile of academic reading texts and vocabulary profile of students' essay writing in AWL. The result of the correlational analysis indicates the $r_{\text {table }}$ is 0.9500 for $\alpha 0.05$ and $d f 2$. Since the $r_{\text {value }}$ is smaller than the value of the $r_{\text {table }}$, the alternative hypothesis of the research is rejected and accepts the null hypothesis. It means that there is no significant correlation between the variables correlated.

The result is in line with the students' perspective on what they have done to improve their vocabulary. Most of their answers said that they improve their vocabulary mostly not from reading their academic textbook but from other inputs such as joining English meeting club, listening music, watching movie, and so forth. In addition, most of them do not like reading academic textbook because it is such boring activity and so many difficult words, they do reading just for task. As one of students asserted, "I read my academic textbook just sometimes if there is a task" (R15-d). The other said, 
Volume I, Number 01, June 2015

"I like listening music, so I improve my vocabulary through listening music, but I also cannot deny, that reading book can also improve my vocabulary, but I easily forget the words from the book than listening music" (R2-c).

Nation and Waring (2004) believed that reading provides favorable conditions for vocabulary learning, both in repetition of vocabulary and decreased density of unknown words in texts. Of such skills as listening, speaking, reading and writing, reading is stipulated as the priority of teaching in the College English Syllabus. In addition, Laufer (1998) argued that only 95 percent coverage of a text would be sufficient for reasonable comprehension. This means that, comprehending 95 percent of a text makes a reader gaining at least around 12,000 words families.

Now that Du Hui (2004: 577) argued that 'reading helps to enlarge students' vocabulary, but to be meaningful the amount of reading must be increased'. It is inferred that the more a student read, the more their vocabulary will develop, and the more they understand the meaning of a text. Therefore, the students need to use their academic textbook as the input for their vocabulary development more frequently.

\section{d. The students' opinion on lextutor as a VP web tool analyzer towards academic essay writing}

\section{1) Benefit of VP web tool}

A web tool as an $e$-learning product is commonly perceived as a shopisticated equipment used in language learning. Although the tool such as lextutor was not created for learning purposes, the functions can be targeted at the improvement of knowledge about academic vocabulary that should largely be used in academic writing. One of the current research's aims is to seek for students' opinion about benefits the students can get by using VP web tool as in the lextutor in writing academic essays. Through an interview, it was found the majority of the students saw the VP web tool as a brand new equipment that they had not used before, and could use to self-assess their vocabulary level. As one of the students asserted, "Analyzing vocabulary levels through lextutor I think it's great. I have not done it before. Thus, when I opened this and analyzed my vocabulary, I realized that my vocabulary is still limited." (R7-a). Thus, VP web tool can help students find their vocabulary level and assist them evaluate their academic essays.

Although the opinions were dominated by positive views, some sceptical thoughts arose through the interview. As one of the students asserted, 
Nur Aliyah Nur, Analyzing Vocabulary Level Of The Students' Essay Writing and Academic ...

"That is a good program, but the program doesn't provide a correction or give alternative words to our writing, it just marks the level of each word. If so, I really hope that program should give alternative words." (R4-a).

In such a case, $\mathrm{R} 4$ found the tool as a good program but he/she did not fully understand the true functions of the tool. The tool, however, was not created as a word checker that was able to flag any mistake, neither to provide alternative words as in a thesaurus.

Another critical opinion towards such tool was asserted by R21:

"It is helpful but in my point there is still disadvantage of it. If it is still count the repeated words, bow can we know how much exactly our total original words?" (R21-a).

The conclusion can be made based on the synthesis of collective opinions of 30 students from the interview that the VP web tool is good and gives a lot of benefit to students to assess their vocabulary level when dealing with academic essay writing.

\section{2) Changes in students' perspectives of word choices in writing academic essays}

The students were also questioned about their perspectives of their word choice before and after being introduced by lextutor_and how such tool changes their perspectives when dealing with academic essays. The results of the interview show that all the students admitted to have low level of vocabulary which means that they used common words in a large extent or exceeded the maximum percentage of K1. Consequently, they used only a few academic word lists (AWL) in their essays and made them considered to be unacademic.

Below are some of the students' assertion during the interview about their opinion or perspectives toward their academic vocabulary level after having been introduced the VP web tool. R1 for example asserted that:

"AfterI use the LT and talking about my vocabulary level I think it is pretty good level but I need to learn more about it and master the vocabulary levels. The vocabulary levels of my four writings are different maybe because the topic are different and also because I write them before and after learning about LT. Learning about it, makes me know and understand about vocabulary level, especially about academic vocabulary."(R1-b)

R1 found that his writing was composed by a pretty good level of vocabulary but then felt challenged of mastering the vocabulary level after being introduced to the VP web tool. R1 also admitted that he/she got knowledge about academic vocabulary after self-analyzing his essays. His assertion implies that his/her perspectives toward the academic essays performance had changed positively. 
Volume I, Number 01, June 2015

R4 admitted that after doing some analyses through VP web tool, his vocabulary was found to be low. Knowledge about the four vocabulary levels he got from the tool through which he intended to apply in his thesis. Thus, intruducing VP web tool to R4 resulted in certain motivation of applying his new knowledge into his future academic writing tasks. Here is the excerpt:

"Hahahahah......, talking about my vocabulary level, absolutely, it is still low and far from the perfect when I try to analyze it by using LT. The web is very good because after knowing it, I can improve my vocabulary level and know the four kinds of those levels. I can apply it in my thesis writing later too. Of course, the theme affects the word choice and vocabulary level." (R4-b)

Using common words (K1) in academic essays would be marked blue at the VP web tool and were expected not to exceed $70 \%$ of the word limit. R6 did not care the words she used in her essays of whether they were academic or common. After applying the analysis model of VP web tool, she got a new perspective that she should be more careful when using words in academic essays. It implies that VP web tool has a different way of developing students' awareness of the importance of taking into account the type of words they should use in their academic essay.

Overall, all the students found the VP web tool as a gate to their awareness of the vocabulary level they commonly used when dealing with academic essays. The synthesis of the students' assertions in terms of perspectives dealing with vocabulary level is that they have awareness of low vocabulary level and started to care about the vocabulary they used in writing academic tasks. They also changed their ways of writing and have intention to improve and develop their vocabulary level as they have the basic knowledge of it. The tool motivated them to learn more and to watch their academic words level gradually. Thus, introducing VP web tool to students is a first step towards the establishment of assisting students cope with their problems in writing academic essays.

\section{B. CONCLUSION AND SUGGESTION}

Based on the findings and discussion, the researcher concludes that: (1) based on the the series of analysis results, the students show various degrees of VP in the four essay writing, and based on the series analysis results of vocabulary level of academic textbooks, those four academic textbook are qualified enough to be academic input for the university students since the vocabulary levels are closer to the standard percentage of vocabulary levels; (2) based on the findings of the effect of introducing the web to the students' vocabulary levels, it can be concluded that 
Nur Aliyah Nur, Analyæing Vocabulary Level Of The Students' Essay Writing and Academic ...

the treatment is not effective enough in improving the students' vocabulary levels since the trendlines did not show the normal pattern of time-series graphic line design; (3) based on the findings of the correlation of the vocabulary level of the students' essay writing and their academic textbook, it reveals that there is no significant correlation between the variables correlated; and (4) based on the synthesis of collective opinions of 30 students from the interview, it shows that the VP web tool is good and gives a lot of benefit to students to assess their vocabulary level when dealing with academic essay writing.

As the results of the study reveal that introducing VP web tool to students is the first step towards the establishment of assisting students cope with their problems in writing academic essays, the researcher suggests: (1) Introducing the VP web tool is highly recommended as the vocabulary monitor and assessment to the students and lecturers which motivate and engage the students to fully aware to their vocabulary development; (2) Analyzing vocabulary levels utilizing the web is very useful not only for the students and lecturers but also the researchers who concern on the vocabulary analysis, assessment, and development; (3) Since only introducing this web is not effective enough for learning and improving vocabulary, it is highly recommended to not only introduce this web but also explaining and teaching the vocabulary levels to the students in vocabulary, reading, or writing classes; (4) As the findings of this research showed that the students' vocabulary level in term academic word was still low or below the standard, so that the lecturers and all syllabus designers need to create appropriate learning subjects and materials that improve and develop the students' vocabulary especially the academic words; (4) The students should be engaged and notified to fully aware of their reading text. So that reading their academic textbook is not only for the sake of fulfilling their tasks but also for their vocabulary input; (5) Related to the students' academic textbook, the teachers or lecturers should fully heed in selecting the textbook that appropriate with the students' level and innovate the way they teach reading; (6) To other researchers who want to use the web as his/her instrument, it is recommended to make comparative study of analysis results based on the web or it will be more useful to make vocabulary level handbook as the guide in introducing, learning, and improving vocabulary; (7) As a matter of fact, this web still has some weaknesses such as counting the repeated words, having no alternative word choice, and having no grammatical correction and word diction, thus, it is highly recommended to everyone 
who is anxious to use this web to fully aware of those weaknesses and give supporting materials or learning activities to cover those weaknesses.

\section{REFERENCES}

Aziez, Furqanul. 2011. Examining the vocabulary levels of Indonesia's English national examination texts. Asian EFL Journal Press51(2)16-29.

Chen, Pi-Ching., Hu, Kai-Cheng., \& Chang, Jhen-Ying Ho. 2009. A study of academic vocabulary used in the abstracts of business and management journals. Taiwan International ESP Journal 1(1)51-76.

Chujo, K., \& Oghigian, K. 2009. How many words do you need to know to understand TOEIC, TOEFL \& EIKEN? An examination of text coverage and high frequency vocabulary. The Journal of Asian TEFL 6 (2), 121-148.

Cobb, T. 2002. Web Compleat Lexical Tutor / Vocabulary Profile. Retrieved on September 4, 2011 from www.lextutor.ca

Coxhead, A. 2000. A new academic word list. TESOL Quarterly34 (2) 213-238.

Du Hui. 2004. Reflections on vocabulary size of Chinese university students. International Education Journal 5 (4) 571-581.

Gay, L. R., Mills, Geoffrey E., \& Airasian, Peter. 2006. Educational Research: Competencies for Analysis and applications. $8^{\text {th }}$ Edition. New Jersey: Pearson Education, Inc.

Laufer, B. 1998. The development of passive and active vocabulary in second language: same or different. Applied Linguistics 19 (2) 255-271.

Laufer, B., \& Nation, P. 1995. Vocabulary size \& use: lexical richness in 12 written productions. Applied Linguistics 16 (3) 307-322.

Madsen, S. Harold. 1983. Techniques in Testing. New York: Oxford University Press.

Mukundan, Jayakaran. \& Hussin, Anealka Aziz Hussin. 2006. Automatic and semiautomatic processes of wordsmith 3.0 as a textbook evaluation instrument: a case study involving one Malaysian secondary school textbook. TEFLIN: Teaching English as a Foreign Language in Indonesia Journal 17 (2) 101-121.

Nation, P., \& Waring, R. 2004. Vocabulary size, text coverage and word lists. Retrieved on September 4, 2011 from http://www.wordhacker.com

Nation, I.S.P. 1990. Teaching and Learning Vocabulary. New York: Newbury House Publishers.

I.S.P. 2001. Learning Vocabulary in Another Language. Cambridge: Cambridge University Press. 